\title{
Farklı ağaç türlerinde çeşitli tomruk hacim formüllerinin karşılaştırılması
}

Comparison of various log volume formulas for different tree species

\author{
Abdurrahman ŞAHİ ${ }^{1}$ \\ Salih Soner KORKMAZ ${ }^{2}$
}

${ }^{1}$ Artvin Coruh Üniversitesi, Orman Fakültesi, Artvin

${ }^{2}$ Orman Genel Müdürlüğü, Adana Orman Bölge Müdürlüğü, Adana

Sorumlu yazar (Corresponding author) Abdurrahman ŞAHIN

asahin84@windowslive.com

Geliş tarihi (Received)

01.03.2021

Kabul Tarihi (Accepted)

21.04.2021

Sorumlu editör (Corresponding editor) Mustafa BATUR

mustafabatur01@ogm.gov.tr

Atıf (To cite this article): Sahin, A, Korkmaz, S . (2021). Farklı ağaç türlerinde çeşitli tomruk hacim formüllerinin karşılaştırılması . Ormancılık Araştırma Dergisi , 8 (2), 171-179. DOI: https://doi.org/10.17568/ogmoad.888129

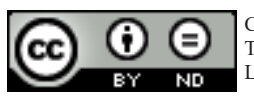

Creative Commons Atıf Türetilemez 4.0 Uluslararas Lisansı ile lisanslanmıştır.

\section{Öz}

Çalışmada, tomrukların hacimlendirmesinde kullanılan sekiz farkl1 hacim formülünün karşılaştırılması amaçlanmıștır. Orta Yüzey (Huber), Uçlardaki Yüzeyler Ortalaması (Smalian), Newton-Riecke, Uçlardaki Çaplar Ortalaması, Hossfeld, Bruce, Patterson-Doruska ve Centroid formüllerinden elde edilen sonuçlar karşılaştırılmıştır. Üç farklı ağaç türünden (kızılçam (Pinus brutia), karaçam (P. nigra) ve sedir (Cedrus libani)) kesilmiş olan, 3'er metre (m) uzunluğundaki 115 adet tomruk kullanılmıştır. Tomrukların önce $0,5 \mathrm{~m}$ arayla çapları ölçülmüş; sonra her bir seksiyon hacmi Smalian formülü kullanılarak bulunmuş ve toplam tomruk hacmi elde edilmiştir. Ardından, 8 farklı formül ile hesaplanan tomruk hacimleriyle; gerçeğe en yakın olarak bulunan hacim değerleri karşılaştırılmıştır. Çalışma sonucunda, her ağaç türü için Huber, Newton-Riecke ve Uçlardaki Çaplar Ortalaması formüllerinin hata değerleri sıfırdan farksız $(p>0,05)$ çıkmıştır. Ayrıca, karaçam tomruklarını hacimlendirmede Centroid ve sedir tomruklarını hacimlendirmede de Smalian formüllerinin hataları da sıfırdan farksız olup $(p>0,05)$ kullanılabilir olduğu belirlenmiştir. Bu formüller arasında, hacimlendirme hatasını minimize eden en uygun formüller ve hata değerleri sırasıyla (ortalama hata, ortalama mutlak hata yüzdesi ve toplam hata yüzdesi), kızılçam tomruklarında Newton-Riecke $(0,441,0,608$ ve 0,111$)$, karaçam tomruklarında Centroid $(-0,444,0.901$ ve $-0,141)$, ve sedir tomruklarında ise uçlardaki çaplar ortalamas1 (-0,104, 0.811 ve -0,038) şeklinde bulunmuştur.

Anahtar Kelimeler: Tomruk, hacim, kızılçam, karaçam, sedir

\begin{abstract}
In this study, it is aimed to compare eight different volume formulas used in volumizing logs. The results obtained from Midface (Huber), Mean Surfaces at Ends (Smalian), Newton-Riecke, Mean Diameters at the Ends, Hossfeld, Bruce, Patterson-Doruska and Centroid formulas were compared. In the scope of the study, 115 logs each 3-meters (m) long, cut from three different tree species (Calabrian pine (Pinus brutia), Black pine (P. nigra) and Cedar (Cedrus libani)), were used. First, the diameters of the logs were measured at $0.5 \mathrm{~m}$ intervals, then each section volume was found using the Smalian formula and the total $\log$ volume was obtained. Then, log volumes calculated with 8 different formulas were compared with the volume values found closest to the truth. As a result of the study, the error values of Huber, Newton-Riecke and Mean Diameters at the Ends formulas were found to be indistinguishable from zero $(p>0.05)$ for each tree species. In addition, it was determined that the Centroid formula for volumizing black pine logs and Smalian formula for volumizing cedar logs were also non-zero $(\mathrm{p}>0.05)$, and they are usable. Among these formulas, the most suitable formulas that minimize the volumizing error and error values are respectively (mean error, mean absolute error percentage and total error percentage), Newton-Riecke $(0.441,0.608$ and $0.111)$ for calabrian pine $\operatorname{logs}$, Centroid $(-0.444,0.901$ and -0.141$)$ for black pine logs, and the average diameters of the ends for cedar logs $(-0.104,0.811$ and -0.038$)$.
\end{abstract}

Key words: Log, volume, calabrian pine, black pine, cedar 


\section{Giriş}

Ormanların sunduğu çeşitli fonksiyonların başında gelen ve en fazla önem arz eden durumda olan ekonomik yönüdür. Ormanın ana ürünü olan ve işletme sermayesinin büyük bir bölümünü oluşturan ağaç serveti, Orman İşletme Müdürlügüünün temel girdisi olup o Orman İşletmesinin var oluşunu ortaya koyan en temel öğedir (Yeşil, 1992; Yavuz, 1999a; Kapucu, 2004, Kahriman ve ark., 2017).

Orman ürünleri; yükte ağır, pahada hafif, taşınması ve depolanması bir hayli zor olmasına karşın, kullanım alanı oldukça geniştir. Sahip oldukları önemden dolayı, orman ürünlerinin fiyatı; türüne, yöresine ve mevsimine göre farklılık göstermektedir. Zira orman ürünleri, nüfus artışıyla orantılı olarak arttırılamayacağı için, fiyatları sürekli olarak yükseliş göstermektedir (Kalıpsız, 1982, Şahin ve ark, 2017). Yani ormanların değerlerinin ekonomik olarak ortaya konması için sunduğu ürün ve hizmetleri mümkün olduğunca doğru şekilde hesaplamak gerekmektedir (Şahin, 2015). Özellikle, parasal değerleri ve kullanım yerleri birbirinden önemli derecede farklı olan odun ürünlerinin, tek ağaç ve hektardaki dağılımlarının önceden bilinmesi ile birbirinin yerine konulmasından doğabilecek önemli zararlar önlenebilecektir (Sun ve ark., 1978). Bu sebeple orman ürünlerinin çeşitlerini ve miktarlarını doğru şekilde belirleyebilmek; ayrıca Orman İşletmeleri tarafindan pazarlanan büyük çaplı tomrukların hacimlerini de (Kahriman ve ark., 2016) en doğru şekilde tespit etmek; gerek orman planlayıcılar ve gerekse araştırmacılar açısından oldukça önemlidir.

Kullanım durumuna göre odunlar; 'Yapacak Odunlar' ve 'Yakacak Odunlar' olmak üzere ikiye ayrılmaktadır. Yapacak odunlar yuvarlak odunlar olup çeşitleri; tomruk, direk, yuvarlak sanayi odunu, sırık ve çubuktur (Günay ve Çancı, 1982). İşte bu sınıflandırma içerisinde ekonomiye en çok katk1 sağlayan ürünler; yapacak olarak satılan orman ürünleridir. Bu suretle, yapacak odunları en doğru şekilde hacimlendirmek; doğabilecek zararları da önleyecektir.

Ağaç hacim tabloları; ağaçların göğüs çapı (cm) ve boyu (m) gibi kolay ölçülebilen ağaç değişkenleri yardımıyla hacimini tahmin eden tablolardır (Kapucu ve ark., 2002). Ağaç hacim tablolarının hazırlanması veya hacim eğrilerinin çizimi için örnek ağaçlardan elde edilen veriler yardımıyla modeller geliştirilir. (OGM, 1991; Carus, 2002). Ormanc1lıkta alım-satım, ağaç hacmi ve hacim artımı envanteri ve bilimsel araştırma vb. işlerde tek ağaçtan elde edilecek her türlü odun ürün sınıflarının hacmini bulmak için çeşitli hacim tayini formülleri vardır (Diker, 1946; Miraboğlu,1959; Fırat, 1973; Kalıpsız, 1984). Gövde bütünü veya parçasına ilişkin hacmin hassas şekilde belirlenebilmesi; kullanılacak hacim yöntemindeki ölçmelerin sayısına ve yerine bağlıdır.

Carus (2002); “Odun hacminin tayini için türetilen formüllerin çoğu, uygulamanın istediği özelliklere sahip olmadığından uygulamada yer bulamamıştır. Bazı formüllerin verdiği sonuç daha hassas fakat uygulamasi zordur ya da bunun tam tersi durum söz konusudur. Hacmin tayini için en az ölçmeyi gerektiren formül, basit ve kullanışlıdır (Diker, 1946; Miraboğlu,1959; Fırat, 1973; Akgür, 1982; Kalıpsız, 1984;)". Ülkemiz Orman İşletmelerinde tomruk hacimlendirmede orta yüzey (Huber) formülü kullanılmaktadır. Ancak, en hassas ölçümün yapıldığı formül Newton-Riecke ise dönel cisimlerden silindir, koni, paraboloid ve nayloid için doğru sonuç vermesi nedeniyle, diğerlerine kıyasla daha duyarlıdır (OGM 1991; Diker, 1946; Kalıpsız, 1984). Ağaç gövdesini, eşit uzunluk veya boyun belirli oranındaki uzunluğu şeklinde bölümlere (seksiyonlara) ayırarak hacimlendirmek de mümkündür. Bu yöntem; bilimsel araştırma ve meşcere hacminin tayini gibi amaçlarla kesilen ağaçların ya da uzun ve değerli olan ağaç gövdelerindeki hacmin tayininde kullanılmaktadır (Diker, 1946; Miraboğlu,1959; Fırat, 1973; Akgür, 1982; Kalıpsız, 1984; Carus, 2002)

Hacim formüllerinin karşılaştırılması konusunda ulusal ve uluslararası birçok araştırma yapılmıştır. Bu çalışmalardan ülkemizde; Yavuz (1999b), dişbudak, Doğu ladini, ve Doğu kayını tomruklar1nı hacimlendirmede Huber, N.Riecke, Smalian ve Hossfeld formülleri yerine Centroid yöntemini; Carus (2002), Doğu Kayını tomruklarını hacimlendirmede Huber, Smalian'a nazaran Newton-Riecke yöntemini; Özçelik (2002) kızılçam ve sedir tomruklarını hacimlendirmede Huber, Smalian, N. Riecke ve Hossfeld yöntemleri yerine Centroid yöntemini; yine Özçelik (2006), farklı uzunluklardaki Toros sediri, Toros göknarı ve kızılçam tomrukların hacimlendirmede Patterson-Doruska yöntemi yerine Bruce ve Smalian yöntemlerini; Güney (2007), farklı uzunluklardaki kızılçam, Toros göknarı ve Toros sediri tomruklarında Huber ve Smalian yöntemleri yerine center of Gravity veya Centroid metodunu; Özçelik ve ark. (2008), Toros göknarı ve kızılçam tomruklarını hacimlendirmede geleneksel Huber, Smalian ve N. Riecke yöntemleri yerine center of Gravity veya Centroid yöntemini ve Durkaya ve Durkaya (2011) da sahilçamı, Doğu kayını, Uludağ göknarı, sedir ve karaçam tomruklarını hacimlendirmede Huber, N. Riecke, Hossfeld, Bruce, P.-Doruska, Smalian 
ve Centroid yöntemleri arasında, tüm türlerde $\mathrm{N}$. Riecke formülünün başarılı olduğunu belirterek, göknar, kayın ve sahilçamı tülerinde ortalama hatalarının sıfırdan farksız çıkan Smalian ve Huber formüllerinin de kullanılabileceğini belirtmişlerdir.

Çeşitli ağaç türlerinde, farklı formüllerin üstünlüklerinin ortaya koyulduğu uluslararası bazı çalışmalar da da; Williams ve ark. (1991), Bruce formülünün kısa ve kalın tomruklarda daha başarılı olduğunu; Wiant ve ark. (1996), Bruce formülünün Smalian'dan daha başarılı olduğunu ve hata miktarının tomruk büyüklüğü ile kalın uç çapına bağlı olarak değiştiğini; Filho ve ark. (2000), ksilometre formülüyle hacim tespit ettiği çalışmada, Huber formülünün Centroid ve N. Riecke'den daha az hata verdiğini belirtmişlerdir. Ayrıca, Wood ve Wiant (1990), Wood ve ark.(1990) ile Wiant ve ark. (1993) Centroid formülü ile bazı formüllerin karşılaştırmasını yapmışlardır. Patterson ve Doruska (2004) da, Bruce formülünün k1sa tomruklarda eksik, uzun tomruklarda ise fazla miktarda hacim hesapladığ1 sonucunu belirtken; Tewari ve Singh (2005) de, Bruce formülünün bazı formüllere göre daha iyi sonuç verdiğini vurgulamışlardır.

Özçelik (2006)'e göre; “tomruk boyu kısaldıkça çap düşüşü azalmakta ve her iki uçtaki yüzey büyüklükleri birbirine yaklaşmaktadır". Buradan hareketle, tomruk boyu uzadığında, çap düşüşündeki artışa bağlı olarak hata oranının artabileceği düşünülmektedir. Bu durum, Güney (2007) tarafından "genellikle, tomruk uzunluğunun artmasına paralel olarak Patterson-Doruska ve Bruce yöntemlerinin güvenilirliği azalmaktadır” şeklinde belirtilmiştir.

$\mathrm{Bu}$ yüzden, çalışmamızda boy değişkeni standart olacak şekilde, üç ağaç türünde de orta uzunlukta (3 m) kesilmiş olan ve orta kalitedeki tomruklar seçilerek; hacimlendirmede, daha önce kullanılan çeşitli tomruk hacmi tayin formüllerinin karş1laştırılması amaçlanmıştır. Adana Orman Bölge Müdürlüğü, Pos Orman İşletme Müdürlüğüne bağlı Akören Orman İşletme Şefliği içerisindeki Değirmencik Orman Deposuna getirilen kızılçam, karaçam ve sedir tomruklarının hacimleri çeşitli formüllere göre bulunmuş ve aralarındaki farklar karşılaştırılmıştır.

\section{Materyal ve Yöntem}

Çalışmada kullanılan tomruklar, ilgili orman deposuna Akören, Pos, Soğukoluk, Söğüt, Yaprakl1, Eğni ve Şamadan Orman İşletme Şefliklerinden gelmekte olup; entegre sanayi başta olmak üzere, çeşitli yapacak orman ürünü fabrikaları tarafından satın alınmaktadır. Burada, çok uzun boylu tom- ruklar istenmemekte ve bu doğrultuda, ilgili şefliklerde yapılan üretim işlerinde tomruklar çoğunlukla $3 \mathrm{~m}$ seksiyonlara ayrılmış şekilde depolara getirilmektedir.

\subsection{Materyal}

Çalışma alanı; Adana Orman Bölge Müdürlüğü, Pos Orman İşletme Müdürlüğüne bağlı Değirmencik Orman Deposudur. Depo, 2018 yılında açılmış olup denizden yüksekliği 1045 m'dir. Çalışmanın materyalini ise bu depoya farklı tarihlerde getirilen 45 kızılçam (Pinus brutia), 30 karaçam (P. nigra) ve 40 sedir (Cedrus libani) tomruğu oluşturmaktadir.

Yapılan ölçümlerde tomruk ve seksiyon uzunlukları şerit metre ile cm hassasiyetinde; tomruk çapları da mm hassasiyetinde çap ölçer ile yapılmıştır. Ayrıca, ilgili ölçümler kullanılarak, hacim hesaplaması için MS Excel ve istatistik analizlerin yapılması için de, SPSS 19.0 istatistik paket programı kullanılmıştır (IBM, 2010).

\subsection{Yöntem}

Değirmencik Orman Deposunda seçilen her bir k1zılçam, karaçam ve sedir tomruğu üzerinde hacimlendirme için kullanılan formüllerde yer alan parametreler $\left(0,5 \mathrm{~m}\right.$ aralıklarda gövde çapları $\left(\mathrm{d}_{0}, \mathrm{~d}_{0,5}\right.$, $\mathrm{d}_{1}, \mathrm{~d}_{1,5}, \mathrm{~d}_{2}, \mathrm{~d}_{2,5}, \mathrm{~d}_{3} \ldots, \mathrm{d}_{\mathrm{n}}$ ve $\mathrm{d}_{1 / 3}$, ayrıca q formülüyle hesaplanan çap değeri çift taraflı olarak) ve tomruk uzunluğu (L) ölçülmüş ve kayıt altına alınmıştır.

Ardından ölçüm değerleri MS Excele girilmiş ve ilk olarak her bir seksiyonun (0,5 m olan) hacmi hesaplanıp toplanarak tomrukların gerçeğe en yakın hacim değerleri bulunmuştur. Ardından, ilgili hacim formüllerine (denklem 1-8) göre ayrı ayrı hacimlendirme yapılmıştır. Sonrasında ise, gerçeğe en yakın hacim değerleri ile diğer formüllerle hesaplanan hacim değerleri karşılaştırılmıştır. Bu karşılaştırma için, çalışma kapsamında kullanılan her bir formüle göre hesaplanmış tomruk hacim değerlerinin ortalama hata $(\mathrm{OH})$, ortalama mutlak hata yüzdesi (OMHY) ve toplam hata yüzdesi (THY) değerleri; her bir tomruk türü için (kızılçam, karaçam ve sedir tomrukları için) ayrı ayrı olmak üzere aşağıdaki formüllere göre hesaplanmıştır. Bu hesaplamalardan sonra da, her bir formüle göre hatası en küçük olandan en yüksek olan doğru formüller kendi içlerinde 1'den 8'e kadar numaralandırılmıştır. Son olarak da OH, OMHY ve THY formüllerindeki numaralar toplanarak genel sıralama oluşturulmuş ve buna göre en düşük puanı alan formül, en başarılı kabul edilmiştir (Tablo 3). 


$$
\begin{aligned}
& (\mathrm{OH}) \bar{D}=\frac{\sum\left(V_{g}-V_{t}\right)}{\mathrm{n}} \\
& \text { OMHY }=\frac{\sum\left|V_{g}-V_{t}\right|}{\sum V_{g}} \times 100 \\
& T H Y=\frac{\sum V_{g}-\sum V_{t}}{\sum V_{g}} \times 100
\end{aligned}
$$

Denklemlerde; $\mathrm{V}_{\mathrm{g}}=$ Gerçek tomruk hacmi $\left(\mathrm{dm}^{3}\right)$, $\mathrm{V}_{\mathrm{i}}=$ İlgili formülden hesaplanan tomruk hacmi $\left(\mathrm{dm}^{3}\right)$ ve $\mathrm{n}=$ örnek tomruk sayısını (adet) temsil etmektedir.

Mevcut formüllerin uygunlukları denetlenirken; parametrik test varsayımlarından biri olan "grup varyanslarının homojenliği" sağlanması durumunda; seksiyon yöntemiyle hesaplanan hacim değeriyle $\left(\mathrm{V}_{\mathrm{g}}\right)$, ilgili formüller yardımıyla hesaplanan hacim değerleri $\left(\mathrm{V}_{\mathrm{i}}\right)$ arasında tek tek "Eşleştirilmiş Örneklem T-Testi (Paired Samples T-Test)" yapı1miştır.

\subsection{Tomruk hacimlendirmede kullanılan formüller}

Çalışmada, tomruk hacimlendirmede geleneksel olan ve pek kullanılmayan bazı formüller değerlendirilmiștir. Bunlar; 1) Huber (Orta Yüzey) Formülü, 2) Smalian, 3) Newton-Riecke Formülü, 4) Uçlardaki Çaplar Ortalaması (Ç.O.), 5) Hossfeld, 6) Bruce (Bruce, 1982), 7) Patterson-Doruska (Patterson ve Doruska, 2004) ve 8) Centroid formülleri olup, içerikleri aşağıda açıklanmıştır (Özçelik, 2002; Özçelik, 2006; Li ve ark., 2015).

$$
\begin{array}{lll}
\text { Huber } & V=M L \\
\text { Smalian } & V=((B+S) / 2) L \\
\text { N.-Riecke } & V=((B+4 M+S) / 6) L \\
\text { Uçlardaki Ç.O. } & V=\frac{\pi}{4} \cdot L\left(\frac{d_{0}+d_{n}}{2}\right)^{2} \\
\text { Hossfeld } & V=((3 G+S) / 4) L \\
\text { Bruce } & V=(0.25 B+0.75 S) L \\
\text { P.-Doruska } & V=((P B)+((1-P) . S)) L \\
\text { Centroid } & V=S L+(1 / 2) b L^{2}+(1 / 3) c L^{2}
\end{array}
$$

\section{Burada;}

$$
\begin{aligned}
& \mathrm{d}_{0}, \mathrm{~d}_{\mathrm{n}}, \mathrm{d}_{0,5:} \quad \text { Tomruğun kalın, ince ve orta uç çapını, } \\
& \mathrm{d}_{1 / 3} \text { : Tomruk uzunluğunun 1/3'ündeki çap1 (Şekil 1), } \\
& \text { V: Tomruk hacmini, } \\
& \text { L: } \quad \text { Tomruk boyunu (m), } \\
& \text { M: } \quad \text { Tomruk ortasındaki göğüs yüzeyini }\left(M=\frac{\pi}{4} d_{0,5}^{2}\right) \text {, } \\
& \text { B: Tomruğun kalın ucundaki göğüs yüzeyini (gy), } \\
& \text { S: Tomruğun ince ucundaki gy, } \\
& \text { G: Kalın uç tarafindan tomruk uzunluğunun 1/3'üne } \\
& \text { denk gelen gy, } \\
& \text { Tomruğun kalın uç tarafindan itibaren tomruk } \\
& \text { C: } \quad \text { uzunluğunun q mesafesindeki ve tomruk hacmini } \\
& \text { iki eşit parçaya bölen noktadaki gy, } \\
& \text { P. } \quad 0,15+136 /\left(0,394 \cdot d_{0}\right)^{3}+0,002(3,289 . L) \text { formülüyle } \\
& \text { P: } \quad \text { hesaplanan değeri, } \\
& \text { b: } \quad\left(\mathrm{B}-\mathrm{S}-\mathrm{CL}^{2}\right) / \mathrm{L} \text { formülüyle hesaplanan değeri, } \\
& \text { c. } \quad(B-C(L / e)-S(1-L / e)) /\left(L^{2}-L e\right) \text { formülüyle hesaplanan } \\
& \text { c: değeri, } \\
& \text { q: } \quad \text { L- }\left(\left(\left(\left(\left(\left(d_{0} / d_{n}\right)^{4}+1\right)^{0,5}-2^{0,5}\right) /\left(2^{0,5}\left(\left(d_{0} / d_{n}\right)^{2}-1\right)\right)\right)\right) L\right) \\
& \text { q: } \quad \text { formülüyle hesaplanan değeri } \\
& \text { e: } \quad \text { L-q formülüyle hesaplanan değeri ifade etmektedir. }
\end{aligned}
$$

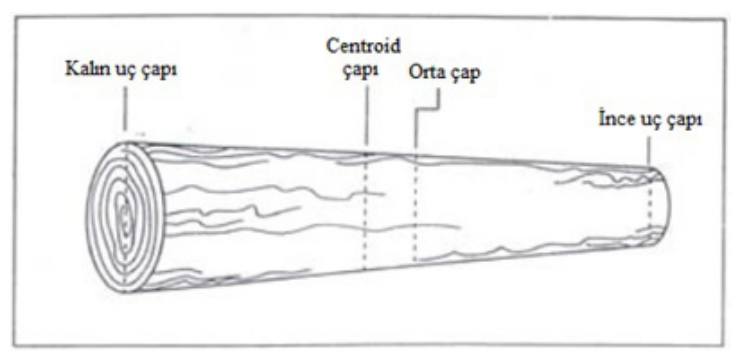

Şekil 1. Arazide tomruk hacim tahminleri için yapılan bazı ölçümler

Shape 1. Some measurements for log volume estimates in the woodyard

\section{Bulgular}

Çalışma kapsamında ölçülmüş olan tüm tomruklara ilişkin çeşitli istatistiksel bilgiler Tablo 1'de; ayrıca seksiyon hacimleri ile her bir formüle göre hesaplanan hacim değerlerine ilişkin çeşitli istatistiksel bilgiler ise Tablo 2'de verilmiştir.

Tablo 1. Örnek tomruklara (3 m) ilişkin bazı istatistik veriler Table 1. Some statistical data on sample logs $(3 \mathrm{~m})$

\begin{tabular}{cccccc}
\hline & & Kalın uç çap $\left(\mathrm{d}_{0}\right)$ & \multicolumn{3}{c}{ Ortalama, (Standart sapma) } \\
\cline { 4 - 5 } Tomruk türü & $\mathrm{N}$ (adet) & $\begin{array}{c}\text { Kalın uç çap }\left(\mathrm{d}_{0}\right) \\
(\mathrm{cm})\end{array}$ & $\begin{array}{c}\text { Orta çap }\left(\mathrm{d}_{0,5}\right) \\
(\mathrm{cm})\end{array}$ & $\begin{array}{c}\text { İnce uç çap }\left(\mathrm{d}_{\mathrm{n}}\right) \\
(\mathrm{cm})\end{array}$ \\
\hline K1zılçam & 45 & $\leq 57,0$ & $42,0(9,0)$ & $40,0(9,1)$ & $38,3(9,0)$ \\
Karaçam & 30 & $\leq 54,0$ & $36,7(10,3)$ & $35,1(10,2)$ & $33,6(0,1)$ \\
Sedir & 40 & $\leq 55,0$ & $34,6(9,1)$ & $32,7(8,8)$ & $30,9(8,7)$ \\
\hline
\end{tabular}

Örnek tomrukların seksiyon yöntemi yardımıyla hesaplanan hacimleri ile diğer hacim formüllerine göre hesaplanan hacimler arasinda bulunan hata miktarları (OH, OMHY ve THY) ve buna ilişkin yapılmış başarı sıralamaları da, Tablo 3'te verilmiştir. 
Tablo 2. Örnek tomruklara ilişkin tanımlayıcı istatistikler Table 2. Descriptive statistics for sample logs

\begin{tabular}{|c|c|c|c|c|}
\hline Tomruk Türü & Hesaplanan Hacim $\left(\mathrm{dm}^{3}\right)$ & Min. $\left(\mathrm{dm}^{3}\right)$ & Maks. $\left(\mathrm{dm}^{3}\right)$ & Ort. $\left(\mathrm{dm}^{3}\right)$ \\
\hline \multirow{9}{*}{ 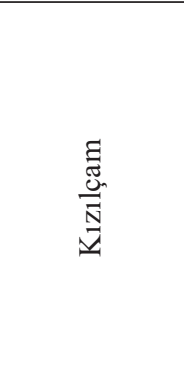 } & Gerçek Hacim & 134,333 & 700,338 & 397,334 \\
\hline & Huber & 130,055 & 712,388 & 395,916 \\
\hline & Smalian & 136,590 & 700,966 & 398,846 \\
\hline & Newton-Riecke & 132,233 & 708,580 & 396,893 \\
\hline & Uçlardaki Ç.O. & 135,648 & 699,494 & 398,028 \\
\hline & Hossfeld & 138,886 & 713,094 & 401,683 \\
\hline & Bruce & 125,286 & 680,772 & 381,678 \\
\hline & Patterson-Doruska & 128,535 & 704,168 & 394,704 \\
\hline & Centroid & 133,518 & 709,996 & 398,754 \\
\hline \multirow{9}{*}{ 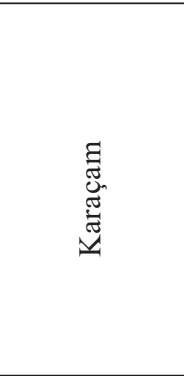 } & Gerçek Hacim & 88,003 & 661,637 & 314,600 \\
\hline & Huber & 85,913 & 661,520 & 312,980 \\
\hline & Smalian & 90,079 & 661,755 & 315,867 \\
\hline & Newton-Riecke & 87,301 & 661,598 & 313,943 \\
\hline & Uçlardaki Ç.O. & 89,549 & 661,520 & 315,248 \\
\hline & Hossfeld & 89,726 & 664,743 & 318,334 \\
\hline & Bruce & 83,190 & 649,274 & 302,883 \\
\hline & Patterson-Doruska & 92,488 & 654,838 & 310,661 \\
\hline & Centroid & 85,257 & 662,639 & 315,045 \\
\hline \multirow{9}{*}{ 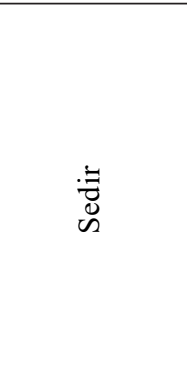 } & Gerçek Hacim & 88,978 & 692,770 & 270,638 \\
\hline & Huber & 88,633 & 699,494 & 269,280 \\
\hline & Smalian & 91,021 & 686,954 & 271,619 \\
\hline & Newton-Riecke & 89,429 & 695,314 & 270,059 \\
\hline & Uçlardaki Ç.O. & 89,549 & 686,718 & 270,742 \\
\hline & Hossfeld & 89,800 & 693,858 & 275,146 \\
\hline & Bruce & 79,540 & 674,237 & 257,354 \\
\hline & Patterson-Doruska & 93,600 & 679,868 & 266,327 \\
\hline & Centroid & 89,623 & 694,698 & 271,902 \\
\hline
\end{tabular}

Hata kriterlerine göre nisbi sıralama yapılmıştır ve tablodan anlaşılacağı üzere; tomrukları hacimlendirmede en az hata veren formüller kızılçam için Newton-Riecke, karaçam için Centroid ve sedir için ise uçlardaki çaplar ortalaması formülleri olarak bulunuştur (Tablo 3).

Tablo 4'te; seksiyon yöntemiyle hesaplanan hacimleri ile diğer formüller vasitasıyla (Huber, Smalian, Newton-.Riecke, Uçlardaki çaplar ortalaması, Hossfeld, Bruce, Patterson-Doruska ve Centroid) hesaplanan hacimlerin; arasında yapılan istatistiksel test sonuçları verilmiştir.

İstatistiksel test sonuçlarına göre, çalışma kapsaminda kullanılan bütün formüllerle hesaplanmış olan hacim değerlerine ilişkin varyanslar homojen bulunmuştur ( $\mathrm{p}>0,05$; (Tablo 4)).

Tablodan da anlaşılacağı üzere; gerçek hacim değerleri ile ilgili formüller kullanılarak hesaplanan hacim değerlerinin arasında 0,05 anlamlılık düzeyinde fark bulunan formüllerin kullanımları (Hossfeld, Bruce, P.Doruska formülleri) önerilmemektedir $(\mathrm{p}<0,05)$.
Ancak, anlamlılık düzeyinde fark bulunmayan formüller içinde ise kızılçam tomruklarını hacimlendirmede Huber, Newton-Riecke ve Uçlardaki çaplar ortalaması formüllerinin; karaçam tomruklarının hacimlendirmede Huber, Newton-Riecke, Uçlardaki çaplar ortalaması ve Centroid formüllerinin; sedir tomruklarının hacimlendirmede ise Huber, Smalian, Newton-Riecke ve Uçlardaki çaplar ortalaması formüllerinin kullanılabileceği sonucuna ulaşılmıştır ( $\mathrm{p}>0,05)$.

Ayrıca, araştırmada kullanılan hacim formüllerinin, farklı türlere ait tomruk hacimlendirmedeki başarıları, oransal fark olarak da araştırılmıştır (Tablo 5).

Tablo 5 incelendiğinde görülmektedir ki; kızılçam tomruklarını hacimlendirmede sırasıyla en başar1lı formüller; Newton-Riecke ( $\% 0,216$ hata ile), Uçlardaki çaplar ortalaması ve Huber formülleri; karaçam tomruklarını hacimlendirmede sırasıyla en başarılı formüller; Centroid (\%0,497 hata ile), Newton-Riecke, Uçlardaki çaplar ortalaması ve Huber formülleri; sedir tomruklarını hacimlendirmede ise sırasıyla en başarılı formüller; Uçlardaki 
Tablo 3. Tomruk gerçek hacimleri ile çeşitli formüllere göre hesaplanan hacimlerin karşılaştırılması Table 3. Comparison of the actual volumes of the log with the volumes calculated according to various formulas.

\begin{tabular}{|c|c|c|c|c|c|}
\hline Tomruk Türü & Yöntem & $\mathrm{OH}$ & $\% \mathrm{OMH}$ & $\% \mathrm{TH}$ & $\sum$ Sira \\
\hline \multirow{8}{*}{ 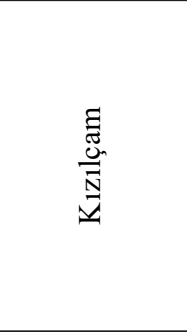 } & Huber & $-1,418 \quad(3)$ & $1,116 \quad(7)$ & $-0,358 \quad(4)$ & $(14)$ \\
\hline & Smalian & $1,512 \quad(5)$ & $0,622 \quad(3)$ & $0,379 \quad(5)$ & (13) \\
\hline & Newton-Riecke & $-0,441 \quad(1)$ & $0,608 \quad(2)$ & $-0,111 \quad(1)$ & (4) \\
\hline & Uçlardaki Ç.O. & 0,694 (2) & $0,593 \quad(1)$ & $0,174 \quad(2)$ & (5) \\
\hline & Hossfeld & $4,349 \quad(7)$ & $1,112(6)$ & 1,083 & (20) \\
\hline & Bruce & $-15,657 \quad(8)$ & $3,940 \quad(8)$ & $-4,102(8)$ & (24) \\
\hline & Patterson-Doruska & $-2,630 \quad(6)$ & 1,029 & $-0,666 \quad(6)$ & (17) \\
\hline & Centroid & 1,420 & $0,798 \quad(4)$ & 0,356 & (11) \\
\hline \multirow{8}{*}{ 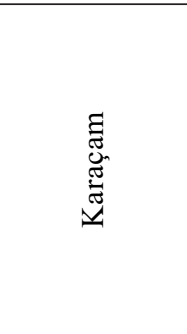 } & Huber & $-1,620(5)$ & $1,093 \quad(5)$ & $-0,518 \quad(5)$ & (15) \\
\hline & Smalian & $1,267 \quad(4)$ & $0,553 \quad(2)$ & $0,401 \quad(4)$ & (10) \\
\hline & Newton-Riecke & $-0,648 \quad(2)$ & $0,621 \quad(3)$ & $-0,205 \quad(2)$ & (7) \\
\hline & Uçlardaki Ç.O. & 0,657 & $0,492 \quad(1)$ & 0,210 & (7) \\
\hline & Hossfeld & $3,733 \quad(6)$ & $1,194(6)$ & 1,173 & (18) \\
\hline & Bruce & $-11,72(8)$ & $3,725 \quad(8)$ & $-3,869 \quad(8)$ & (24) \\
\hline & Patterson-Doruska & $-3,94 \quad(7)$ & $1,485 \quad(7)$ & $-1,268 \quad(7)$ & (21) \\
\hline & Centroid & $0,444 \quad(1)$ & $0,901 \quad(4)$ & $0,141 \quad(1)$ & (6) \\
\hline \multirow{8}{*}{$\begin{array}{l}:= \\
: \\
\mathscr{D}\end{array}$} & Huber & $-1,359 \quad(5)$ & $1,993 \quad(7)$ & $-0,505 \quad(5)$ & (17) \\
\hline & Smalian & $0,981 \quad(3)$ & $0,641 \quad(2)$ & $0,361 \quad(3)$ & (8) \\
\hline & Newton-Riecke & $-0,579 \quad(2)$ & 0,800 & $-0,214 \quad(2)$ & (7) \\
\hline & Uçlardaki Ç.O. & 0,104 & $0,811 \quad(4)$ & 0,038 & (6) \\
\hline & Hossfeld & $4,508 \quad(7)$ & 1,276 & $1,638 \quad(7)$ & (19) \\
\hline & Bruce & $-13,285(8)$ & $3,405 \quad(8)$ & $-5,162 \quad(8)$ & (24) \\
\hline & Patterson-Doruska & $-4,311 \quad(6)$ & $1,625 \quad(6)$ & $-1,619(6)$ & (18) \\
\hline & Centroid & 1,263 (4) & $0,495 \quad(1)$ & $0,465 \quad(4)$ & (9) \\
\hline
\end{tabular}

çaplar ortalaması $(\% 0,055$ hata ile), Newton-Riecke, Huber ve Smalian formülleridir.

Kullanılmaları anlamlı bulunmayan, Hossfeld, Bruce, Patterson-Doruska formüllerinin ortalama hacim farkı oranlarının da yüksek olduğu bu tabloda görülmektedir.

\section{Tartışma ve Sonuç}

Çalışma sonuçları detaylı olarak ele alındığında; üç ağaç türünün tomruklarında da Newton-Riecke, uçlardaki çaplar ortalaması ve Huber formüllerinin hata değerleri; ayrıca karaçamda Centroid ve sedirde de Smalian formüllerinin hata değerleri sıfırdan farksız bulunmuştur ( $p>0,05)$. Bu formüller içinde kızılçamda Newton-Riecke, karaçamda Centroid ve sedirde ise uçlardaki çaplar ortamalası formülleri en az hatayı veren formüller olmuşlardır.

Araştırmanın yapıldığ 1 bölgede orta kalite sınıfındaki kızılçam $\left(\mathrm{d}_{0} \leq 57,0 \mathrm{~cm}\right)$, karaçam $\left(\mathrm{d}_{0} \leq 54,0\right.$ $\mathrm{cm})$, ve sedir $\left(\mathrm{d}_{0} \leq 55,0 \mathrm{~cm}\right)$ türlerinin hacimlendirmesinde:

- Kullanımına fazla rastlanılmayan Hossfeld metodunun tercih edilmemesi gerektiği;

- Ulusal ve uluslararası literatürde çeşitli tomruk hacimlendirmelerinde başarısı denenmiş olan Bruce ve Patterson-Doruska formüllerinin ise farklı boyutlarda veya farklı tomruk türlerinde ve denenmeden tercih edilmemesi gerektiği,

- Çalışmada yalnızca karaçam tomruklarını hacimlendirmede başarılı olan Centroid metodunun; düşük hata oranına sahip olan bir formül olması sebebiyle ve farklı tür ve boyutlardaki tomruklarda denenmek suretiyle tercih edilebileceği,

- Yaygin olarak bilinen Huber, Smalian ve Newton-Riecke formüllerinin, yapılacak çalışmanın ekonomik çerçevesi düzeyinde, yine hata oranı kontrol edilerek kullanılabileceği,

- Çok yaygın bilinmeyip kullanılmayan 'uçlardaki çaplar ortalaması formülünün' ise daha yaygın olarak kullanılabileceği,

- Çalışma sınırları da dikkate alınarak, ilgili ağaç türlerinin, belirtilen ortalama çap değerleri içerisinde benzer sonuçlar vereceği düşünüldüğünde, başarısı ortaya çıkarılan ilgili formüllerin tercih edilebileceği önerilmektedir.

Önceki çalışmalarda; Özçelik (2002), kızılçam ve sedir tomruklarını hacimlendirmede en düşük ha- 
Tablo 4. Tam ölçme ile ikili karşılaştırma t testi sonuçları

Table 4. Paired comparison t-test results with full measurement

\begin{tabular}{|c|c|c|c|c|c|}
\hline \multirow{2}{*}{ Tomruk Türü } & \multirow{2}{*}{ Yöntem } & \multicolumn{2}{|c|}{ Varyansların Eşitliği } & \multicolumn{2}{|c|}{ t-testi sonuçları } \\
\hline & & Levene istatistiği & $\mathrm{p}$ & $\mathrm{t}$ & $\mathrm{p}$ \\
\hline \multirow{8}{*}{ 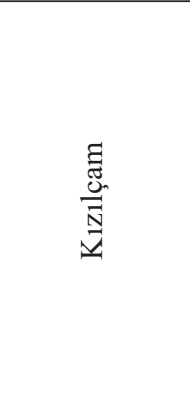 } & Huber & 0,004 & 0,949 & 1,702 & 0,096 \\
\hline & Smalian & 0,001 & 0,981 & $-3,836$ & 0,000 \\
\hline & Newton-Riecke & 0,001 & 0,973 & 0,853 & 0,398 \\
\hline & Uçlardaki Ç.O. & 0,001 & 0,982 & $-1,588$ & 0,119 \\
\hline & Hossfeld & 0,000 & 0,995 & $-10,465$ & 0,000 \\
\hline & Bruce & 0,026 & 0,872 & 13,824 & 0,000 \\
\hline & Patterson-Doruska & 0,010 & 0,922 & 4,060 & 0,000 \\
\hline & Centroid & 0,001 & 0,970 & $-2,418$ & 0,020 \\
\hline \multirow{8}{*}{ 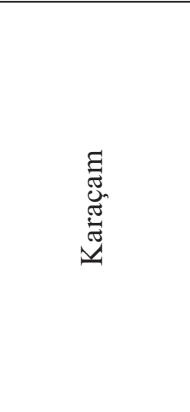 } & Huber & 0,000 & 0,996 & 1,710 & 0,098 \\
\hline & Smalian & 0,000 & 0,991 & $-3,669$ & 0,001 \\
\hline & Newton-Riecke & 0,000 & 0,998 & 1,144 & 0,262 \\
\hline & Uçlardaki Ç.O. & 0,000 & 0,992 & $-1,845$ & 0,075 \\
\hline & Hossfeld & 0,004 & 0,951 & $-6,216$ & 0,000 \\
\hline & Bruce & 0,010 & 0,920 & 11,028 & 0,000 \\
\hline & Patterson-Doruska & 0,009 & 0,925 & 4,997 & 0,000 \\
\hline & Centroid & 0,000 & 0,997 & $-0,612$ & 0,545 \\
\hline \multirow{8}{*}{ 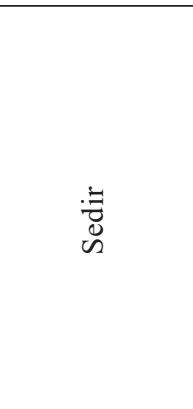 } & Huber & 0,013 & 0,909 & 1,001 & 0,323 \\
\hline & Smalian & 0,001 & 0,981 & $-1,084$ & 0,285 \\
\hline & Newton-Riecke & 0,005 & 0,945 & 0,645 & 0,523 \\
\hline & Uçlardaki Ç.O. & 0,000 & 0,990 & $-0,116$ & 0,908 \\
\hline & Hossfeld & 0,011 & 0,915 & $-5,656$ & 0,000 \\
\hline & Bruce & 0,059 & 0,809 & 8,986 & 0,000 \\
\hline & Patterson-Doruska & 0,044 & 0,835 & 3,543 & 0,001 \\
\hline & Centroid & 0,000 & 0,993 & $-2,486$ & 0,017 \\
\hline
\end{tabular}

Tablo 5. Çeşitli yöntemlere göre hesaplanan tomruk hacimlerinin ortalama fark yüzdeleri (\%) Table 5. Average difference percentages of log volumes calculated according to various methods (\%)

\begin{tabular}{lccc}
\hline \multirow{2}{*}{ Yöntem } & \multicolumn{3}{c}{ Gerçek Hacme Göre Ort. Fark (\%) } \\
\cline { 2 - 4 } & K1z1lçam & Karaçam & Sedir \\
\hline Huber & 0,588 & 1,321 & 0,100 \\
Smalian & $-0,529$ & $-1,085$ & $-0,445$ \\
Newton-Riecke & 0,216 & 0,519 & $-0,081$ \\
Uçlardaki Ç.O. & $-0,279$ & $-0,538$ & $-0,055$ \\
Hossfeld & $-1,292$ & $-3,023$ & $-1,760$ \\
Bruce & 4,241 & 9,924 & 5,329 \\
Patterson-Doruska & 1,480 & 2,782 & 0,964 \\
Centroid & $-0,346$ & $-0,497$ & $-0,646$ \\
\hline
\end{tabular}

tayı Centroid formülünün verdiğini; yine Özçelik (2006), kızılçam ve sedir tomruklarını hacimlendirmede Patterson-Doruska formülünün en başar1lı olduğunu; ayıca Bruce ve Smalian formüllerinin de kullanılabileceğini; Güney (2007), kızılçam ve sedir tomruklarını hacimlendirmede Huber ve Smalian formülleri yerine, daha az hata veren Centroid formülünün kullanılabileceğini, Durkaya ve 
Durkaya (2011)'da, sedir ve karaçam tomruklarını hacimlendirmede Smalian formülünün NewtonRiecke ve Huber formülünden daha az hatalı sonuç verdiğini ortaya koymuşlardır. Çalışmamız ise önceki çalışmalarla kısmen örtüşmektedir. Ancak, daha önceki çalışmaların birçoğuna göre daha fazla yöntemin kullanılması, tomrukların elde edildikleri yöre ve ağaç üzerindeki konum farklılığı ile ayrıca diğer çalışmalarda seçilen ölçüm sıklığının farklı olması nedenleriyle bazı farklılıklar ortaya çıkmaktadır. Ayrıca diğer çalışmalarda denenmemiş olan 'uçlardaki çaplar ortalaması' formülü de çalışmamızda dikkate değer derecede üstünlük sağlamıştır. Bu formülünde göz ardı edilmemesi gerektiği düşünülmektedir.

Çalışma kapsamında önerilen bu formüllerden her birinde ölçülecek değişken sayısı ve çeşidi farkl1dır. Dolayısıyla, orman depolarında ya da kesilmiş olan tomruklar üzerinde yapılacak olan araştırma veya satışlar için hacimlendirmenin önemi ve ekonomik değeri ne kadar büyükse, kullanılacak formül ya da formüller, ölçüm aşamasının zor olması suretiyle ve kaybedilecek zaman da dikkate alınarak tercih edilmelidir. Özellikle Centroid Yöntemi için çok detaylı ölçüm ve hesaplamalar gerekmesi ayrıca Newton-Riecke Yöntemi için de üç farklı noktada çap ölçümü gerekmesi, hacim hesaplama işlemleri sırasında zaman alıcı ve masraflı görülmektedir. Ancak, yapılacak olan çalışmalar, ekonomik getiri yönünden daha çok önem arz ediyorsa, detaylı ölçümlerin yapılması; hacimlendirmedeki hata oranını ve ekonomik kayıpları önleyecektir.

\section{Kaynaklar}

Akgür, 1982. Gövde hacminin tayininde kullanılan formüllerin incelenmesi. İstanbul Üniversitesi (ïU) Orman Fakültesi Dergisi, A(2): 301-365.

Bruce, D. 1982 Butt log volume estimators. Forest Science. 28:489-503.

Carus, 2002. Bazı hacim formüllerinin seksiyon, gövde ve bağıl uzaklıklara göre kıyaslanması. Süleyman Demirel Üniversitesi (SDÜ) Orman Fakültesi Dergisi, A(1): 101-114.

Diker, M., 1946. Ağaç ve Odun Ölçme Bilgisi. Tarım Bakanlığı Orman Genel Müdürlüğü, 230 s, Ankara.

Durkaya, B., Durkaya, A., 2011. Tomruk hacminin hesaplanmasında kullanılan çeşitli hacim formüllerinin karşılaştırılması. Bartın Orman Fakültesi Dergisi, 13(20): 18-22.

Firat, F., 1973. Dendrometri. İÜ Orman Fakültesi yayın no: 93,359 s, İstanbul.

Filho, A.F., Machado, S.A., Carneiro, M.R.A., 2000.
Testing accuracy of log volume calculation procedures against water displacement technigues (xylometer). Canadian Journal of Forest Research, 30(6): 990-997. Doi:10.1139/cjfr-30-6-990.

Günay Z., Çancı F. 1982. Orman Ürünleri Standardizasyonu ve Kübaj., Saydam Matbaası, Ankara.

Güney, İ.H., 2007. Ağaç ve Tomruk Hacimlerinin Tahmininde Kullanılan Bazı Yöntemlerin Karşılaştırılması. SDÜ Fen Bilimleri Enstitüsü, Yüksek Lisans Tezi, Isparta.

IBM Corp. Released 2010. IBM SPSS Statistics for Windows, Version 19.0. Armonk, NY: IBM Corp., USA.

Kahriman, A., Sönmez, T., Şahin, A., Yavuz, M. 2016. A bark thickness model for calabrian pine in Turkey. Proceedings of the 2 nd International Conference on Science, Ecology and Technology, Barcelona, 23-25 August 2016, pp. 661-670.

Kahriman, A., Sönmez, T., Şahin, A., 2017. Antalya ve Mersin Yöresi kızılçam meşcereleri için ağaç hacim tabloları. Kastamonu Üniversitesi Orman Fakültesi Dergisi, 17(1): 9-22.

Kalıpsız A. 1982. Orman Hasılat Bilgisi. İÜ Orman Fakültesi Yayınları, No:3052/328, 349 s, İstanbul.

Kalıpsız, A., 1984. Dendrometri. İÜ Orman Fakültesi yayın no: 354, 407 s, İstanbul.

Kapucu, F. 2004, Orman Amenajman1, 515 s, Karadeniz Teknik Üniversitesi (KTÜ) Yayın No: 215, Trabzon.

Kapucu, F., Yavuz, H., Gül, A.U., Mısır, N., 2002. Kestane Meşcerelerinin Hasılat ve Amenajman Esasları. TOGTAG 2229 nolu TÜBİTAK Projesi, 118 s, Ankara.

Li, C., Barclay, H., Hans, H., Sidders, D., 2015. Estimation of Log Volumes: A comparative study. natural resources Canada, Canadian Forest Service, Canadian Wood Fibre Centre: Edmonton, AB, Canada.

Miraboğlu, M., 1959. Orta Yüzey Formülünün Sihhati ve Devlet Orman İşletmelerimizdeki Tatbikatı. $\dot{I} \ddot{U}$ Orman Fakültesi Dergisi, A(1): 31-47.

OGM, 1991. Orman Amenajman Planlarının Düzenlenmesine, Uygulanmasina ve Yenilenmesine Dair Yönetmelik. Ankara.

Özçelik, R., 2002. Tomruk hacminin tahmininde kullanılan centroid metod ve dört standart formülün karşılaştırılması. SDÜ Orman Fakültesi Dergisi, A(1): 115-120, Isparta.

Özçelik, R. 2006. İstiflenmiş tomruklarda kullanılan hacim formüllerinin karşılaştırılması. SDÜ Orman Fakültesi Dergisi, A(1): 26-32, Isparta.

Özçelik, R., Wiant, Jr, H.V., Brooks, J. R., 2008. Accuracy using xylometry of log volüme estimates for two tree species in Turkey, Scandinavian Journal of Forest Research, 23:3, 272-277. 
Patterson, D.W., Doruska, P.F., 2004. A new and improved modification to Smalian's equation for butt logs. Forest Products Journal. 54: 69-72.

Sun O., Eren M. E., Orpak M. 1978. Temel ağaç türlerimizde tek ağaç ve birim alandaki odun çeşidi oranlarının saptanması. (TÜBİTAK, proje no: TOAG-288), Tarım ve Ormancılık Araştırma Grubu Yayını, Ankara.

Şahin, A., 2015. Mersin Yöresi Saf Kızılçam (Pinus brutia Ten.) Meşcerelerinde Hasılat Araştırmaları. Artvin Çoruh Üniversitesi Fen Bilimleri Enstitüsü, Doktora Tezi, Artvin.

Şahin, A., Sönmez, T., Kahriman, A., 2017. Single entry raw wood products table construction for calabrian pine (Pinus brutia Ten.) in Mersin region. Kastamonu Üniversitesi Orman Fakültesi Dergisi, 17(1): 23-35.

Tewari, V.P., Singh, B., 2005. Comparison of Bruce's formula and other methods for log volume estimation. Indian Forester, 131(7): 917-924.

Wiant. H.V.. Jr.. D.W. Patterson. C.C. Hassler. J.C. Rennie. 1993. Comparison of Bruce's Formula and Other Methods for Estimating the Volume of Butt Logs. Modern Methods of Estimating Tree and Log Volume. Proc.. IUFRO Conference; Morgantown. West Virginia University, June 14-16: 79-85, USA.
Wiant. H. V.. Jr.. D. W. Patterson. C. C. Hassler. G. B. Wood., J. C. Rennie., 1996. Comparison of formulas for estimating volumes of butt logs of appalachian hardwoods. Northern Journal of Applied Forestry, 13(1):5-7.

Williams. J.G.. W.H. McNab. A Clark. III. 1991. Volume Estimators for Pondcypress Butt Logs. Res. Note SE361. USDA Forest Service, Southeastern Forest Experiment Station. Ashville NC. 7pp., USA.

Wood. G.B., H.V. Wiant Jr.. 1990. Estimating the volume of Australian Hardwoods using centroid sampling. Australian Journal of Forestry: 53. 271-274.

Wood. G.B., H.V. Wiant Jr.. R.J. Roy. J.A. Miles. 1990. Centroid sampling: a variant of importance sampling for estimating the volume of sample trees of radiata pine. Forest Ecology and Management: 36. 233-243.

Yavuz, H. 1999a. Taşköprü yöresinde karaçam için hacim fonksiyonlar1 ve hacim tablolar1, Turkish Journal of Agriculture and Forestry, 23, 1181-118.

Yavuz. H. 1999b. Comparison of the centroid method and four standard formulas for estimating log volumes. Turkish Journal of Agriculture and Forestry, 23: 597-602.

Yeşil, A. 1992. Değişik Sıklık ve Bonitetlerdeki Kızılçam Meşcerelerinin Yaşa Göre Gelişimi. İÜ Fen Bilimleri Enstitüsü, Doktora Tezi, İstanbul. 